\title{
EFFECT OF LONG-CHAIN INULIN AND MODIFIED STARCH ON THE PHYSICOCHEMICAL AND RHEOLOGICAL PROPERTIES OF DOOGH (IRANIAN YOGURT DRINK)
}

\author{
M. KARIM ${ }^{\mathrm{a}}$, M. Alimi ${ }^{\mathrm{a} *}$, S. ShoKoOHI ${ }^{\mathrm{b}}$ and F. FAZELI ${ }^{\mathrm{a}}$ \\ ${ }^{a}$ Department of Food Science and Technology, Ayatollah Amoli Branch, Islamic Azad University, \\ P.O.Box 678, Amol. Iran. \\ ${ }^{\mathrm{b}}$ Chemical, Polymeric and Petrochemical Technology Development Research Division, Research Institute \\ of Petroleum Industry, P.O. Box 14115-143, Tehran. Iran
}

(Received: 9 May 2016; accepted: 19 July 2016)

\begin{abstract}
In this research, simultaneous contribution of long-chain inulin (0-2.34\%) and modified starch $(0-0.58 \%)$ on the physical stability and rheological properties of doogh within 30 days of production was studied. Increased concentration of both hydrocolloids redounded to improvements in physical stability, apparent viscosity, flow behaviour, and viscoelastic properties compared to the control sample. Fitting the data to Herschel-Bulkley model showed a decrease in flow behaviour index, while consistency coefficient $(\mathrm{k})$ increased. Furthermore, for samples containing inulin and starch, $G^{\prime}$ was greater than $G^{\prime \prime}$, unlike control sample. Indeed, contribution of long-chain inulin at concentrations above $1.18 \%$ and modified starch at above $0.3 \%$ promote the formation of gel network structure. The expected viscosity increases in the continuous phase in the presence of starch, and also the interactions established between inulin and yoghurt casein aggregates seem to be responsible in the improvement observed in physical characteristics of the product. Among the concentrations studied here, two samples, containing $2 \%$ inulin and $0.5 \%$ modified starch and $1.18 \%$ inulin and $0.58 \%$ modified starch, respectively, were recognized as functional doogh samples presenting premier physicochemical and rheological properties.
\end{abstract}

Keywords: doogh, inulin, modified starch, rheology, food

In different countries, fermented milk beverages have a variety of types and names such as drinking yogurt in Europe, Lassi in India, kefir and kumis in Middle East, ayran in Turkey, and doogh in Iran. Doogh is a favoured cultured beverage of Iranians and other nations living in Eastern Europe, Middle East, and Asia. Nutritional value of 2 cups of doogh is said to be equivalent with a cup of milk (Mircholi Borazagh \& Sedaghat, 2011). Proteins approach their iso-electric point at the low $\mathrm{pH}$ of doogh media and begin to aggregate and participate, which makes the product unstable. To stabilize the dispersion, addition of hydrocolloids or gums is commonly suggested to avoid protein participation and serum separation in fermented products by increasing the apparent viscosity and/or creating sufficient colloidal interactions (electrostatic or steric repulsion) (DICKINSON, 1998). There are several studies investigating the effect of different hydrocolloids such as tragacanth, locust bean gum, pectin, guar, and gellan gum on the physical stability, physicochemical and rheological characteristics of doogh (AZARIKIA \& ABBASI, 2010). Modified starch, specially the acetylated and cross-linked types, are the common thickeners for improvement of stability against low $\mathrm{pH}$, high temperature, and shear stresses that are commonly used in dairy beverage formulations (Ahmed \& Ramaswamy, 2004). Inulin is a natural non-digestible storage polysaccharide

\footnotetext{
* To whom correspondence should be addressed. Phone: +981143217325; e-mail: m.alimi@iauamol.ac.ir.
} 
consisting of $\mathrm{GF}_{\mathrm{n}}$ (fructans starting with glucose) and $\mathrm{F}_{\mathrm{m}}$ (fructans starting with fructose) compounds, in which $\mathrm{m}$ and $\mathrm{n}$ are the numbers of fructose units that are interconnected with $\beta(2-1)$ bounds ending in a terminal glucose (G) molecule (Alimi et al., 2013). Long-chain inulin is also increasingly used as a prebiotic gelling/thickening agent in food products specially dairies (VILLEGAS \& COSTELL, 2007). These properties are attributed to the formation of small aggregates composed of physically interacted inulin micro-crystals that can bind a significant amount of water and thereby create an appropriate mouth feeling, smooth and creamy texture (Bot et al., 2004). TÁrREgA and Costell (2006) investigated the effect of inulin on the rheological and sensory properties of fat-free dairy desserts containing different starch concentrations, and reported a viscosity increase, thixotropic and shear-thinning flow behaviour for all the cases. GLIBOWSKI and KOWALSKA (2012) observed similar results in kefir containing inulin beside decreased caloric value and improved nutritional value.

In this research work, in order to improve the nutritional value of doogh, waxy-maize modified starch and long-chain inulin are added as thickening agent to the conventional formulation. Physicochemical and rheological properties of the prepared samples were studied.

\section{Materials and methods}

\subsection{Materials}

Pasteurized yogurt containing 3\% fat (Alasht dairy products Co., Iran), salt (Taban Co., Iran), long-chain inulin (Frutafit TEX!, Sensus Co., Netherlands), and acetylated di-starch adipate waxy maize starch (Clearam CH2020, Roquette, Italy) were used to prepare the samples.

\subsection{Methods}

1.2.1. Experimental design. "Design-expert" software (version 9) and response surface method were used to design the composition of required samples, analyse the experimental results, and also to introduce optimized runs. Considering the independent variables as longchain inulin $(\mathrm{DP} \geq 23)$ and modified maize starch, response surface method suggested ten samples to be prepared. Minitab software (release 16) was used to the statistical analysis of the experimental results. Error probability value of $\mathrm{P}<0.05$ was considered as significant (Golchooвi et al., 2016).

1.2.2. Preparation of doogh samples. Aqueous hydrocolloid suspensions were prepared introducing $1 \% \mathrm{w} / \mathrm{w}$ salt, inulin, and modified starch to the stirring (EUROSTAR power control-visc 6000 homogenizer, IKA, Staufen, Germany) formulation water in water bath (Nuve Co., Turkey, Model: OTO32) at $80{ }^{\circ} \mathrm{C}$ for $10 \mathrm{~min}$. Samples were stored at $5{ }^{\circ} \mathrm{C}$ for $8 \mathrm{~h}$ in order to allow the hydration process to be completed. Whipped yogurt $55 \% \mathrm{w} / \mathrm{w}(3 \% \mathrm{w} / \mathrm{w}$ fat, $\mathrm{pH}=3.85$ ) was introduced to the suspension homogenized (APV, Denmark) at 150 bar and $60{ }^{\circ} \mathrm{C}$. Pasteurization was conducted at $85^{\circ} \mathrm{C}$ for $1 \mathrm{~min}$, followed by cooling to $10{ }^{\circ} \mathrm{C}$. Samples filled to $250 \mathrm{ml}$ bottles were refrigerated at $4-6{ }^{\circ} \mathrm{C}$. Required measurements were conducted after 30 days on the control sample and ten designed samples prepared.

1.2.3. Serum separation measurement. Samples were filled in graduated cylinder and stored for 30 days at $4{ }^{\circ} \mathrm{C}$. Equation 1 was used to calculate serum separation values at 30 days (GoRJI et al., 2011): 
Serum separation percent $=\frac{\text { Total volume-Participated phase volume }}{\text { Total volume }} \times 100$

1.2.4. Rheological measurements. Rotational viscometer (Viscotech, Spain) equipped with TL5 cylindrical spindle was used for viscosity measurements at 100 r.p.m. (shear rate $=32 \mathrm{~s}^{-1}$ ) for $15 \mathrm{~min}$.

Rheological behaviour of prepared samples was studied using a controlled stress rheometer (Physica MCR 501, Anton Paar GmbH, Austria) with a co-axial cylinder geometry (diameter: $25 \mathrm{~mm}$, height: $40 \mathrm{~mm}$, gap: $1 \mathrm{~mm}$ ) under nitrogen atmosphere at $10{ }^{\circ} \mathrm{C}$. Flow characteristics were investigated fitting shear stress data to Herschel-Bulkley model within the shear rates $0.1-1000 \mathrm{~s}^{-1}$. Frequency sweep tests were conducted in the linear viscoelastic zone at $1 \%$ strain and $0.01-10 \mathrm{~Hz}$.

1.2.5. Particle size analysis. Particle size distribution of samples was investigated by Mastersizer 2000 (Malvern Instrument Ltd, Worcestershire, UK) equipped with quartz cell and laser beam with $\lambda=634 \mathrm{~nm}$. Measurements were made 30 days after sample preparation.

\section{Results and discussion}

\subsection{Serum separation}

Table 1 shows serum separation values of doogh samples. No significant difference is observed between control sample and R5, R7, and R9 ( $>0.05)$, but variations in other samples were significant. Serum separation in all samples declined in the presence of modified starch and long-chain inulin, but finally progressed with storage time.

Table 1. Serum separation results and viscosity of doogh samples with different compositions.

\begin{tabular}{lllcc}
\hline Samples & Starch & Inulin & $\begin{array}{c}\text { Phase separation } \\
\text { after 30 days }(\%)\end{array}$ & $\begin{array}{c}\text { Viscosity } \\
\text { after } 30 \text { days (mPa.s) }\end{array}$ \\
\hline Control & 0 & 0 & $70 \pm 0.00^{\mathrm{a}}$ & $11.2 \pm 1.11^{\mathrm{a}}$ \\
R1 & 0.3 & 1.18 & $58 \pm 1.12^{\mathrm{d}}$ & $19.10 \pm 1.50^{\mathrm{cd}}$ \\
R2 & 0.5 & 2 & $54.50 \pm 0.41^{\mathrm{d}}$ & $19.75 \pm 3.88^{\mathrm{cd}}$ \\
R3 & 0.02 & 1.18 & $64.50 \pm 0.00^{\mathrm{bc}}$ & $15.90 \pm 3.96^{\mathrm{bc}}$ \\
R4 & 0.1 & 2 & $62.50 \pm 0.07^{\mathrm{c}}$ & $17.33 \pm 0.35^{\mathrm{c}}$ \\
R5 & 0.5 & 0.35 & $66.50 \pm 0.07^{\mathrm{abc}}$ & $13.12 \pm 3.23^{\mathrm{b}}$ \\
R6 & 0.3 & 2.34 & $56 \pm 1.41^{\mathrm{d}}$ & $19.90 \pm 0.82^{\mathrm{cd}}$ \\
R7 & 0.3 & 0.01 & $69 \pm 0.00^{\mathrm{a}}$ & $11.55 \pm 10.39^{\mathrm{a}}$ \\
R8 & 0.3 & 1.18 & $57.50 \pm 0 / 07^{\mathrm{d}}$ & $19.45 \pm 11.52^{\mathrm{cd}}$ \\
R9 & 0.35 & $67.50 \pm 0.07^{\mathrm{ab}}$ & $12.57 \pm 3.43^{\mathrm{ab}}$ \\
R10 & 0.1 & 4.18 & $4 \pm 2.12^{\mathrm{e}}$ & $19.95 \pm 2.98^{\mathrm{cd}}$ \\
\hline
\end{tabular}

The results are expressed as mean \pm standard deviation. ${ }^{\text {a,b,c,d,e }}$ : Data followed by the same letter in a column are not significantly different $(\mathrm{P}>0.05)$. 
Serum separation in the samples containing the maximum concentration of one hydrocolloid and the minimum of the other (i.e. R4 and R5) did not show significant difference, whereas serum separation significantly declined at the concentrations above $0.3 \%$ and $1.18 \%$ for starch and inulin, respectively. Unfavourable results were observed in the case of individual addition of the two hydrocolloids, though the effective combinational formulation confirms a synergistic interaction between starch and inulin assisting doogh

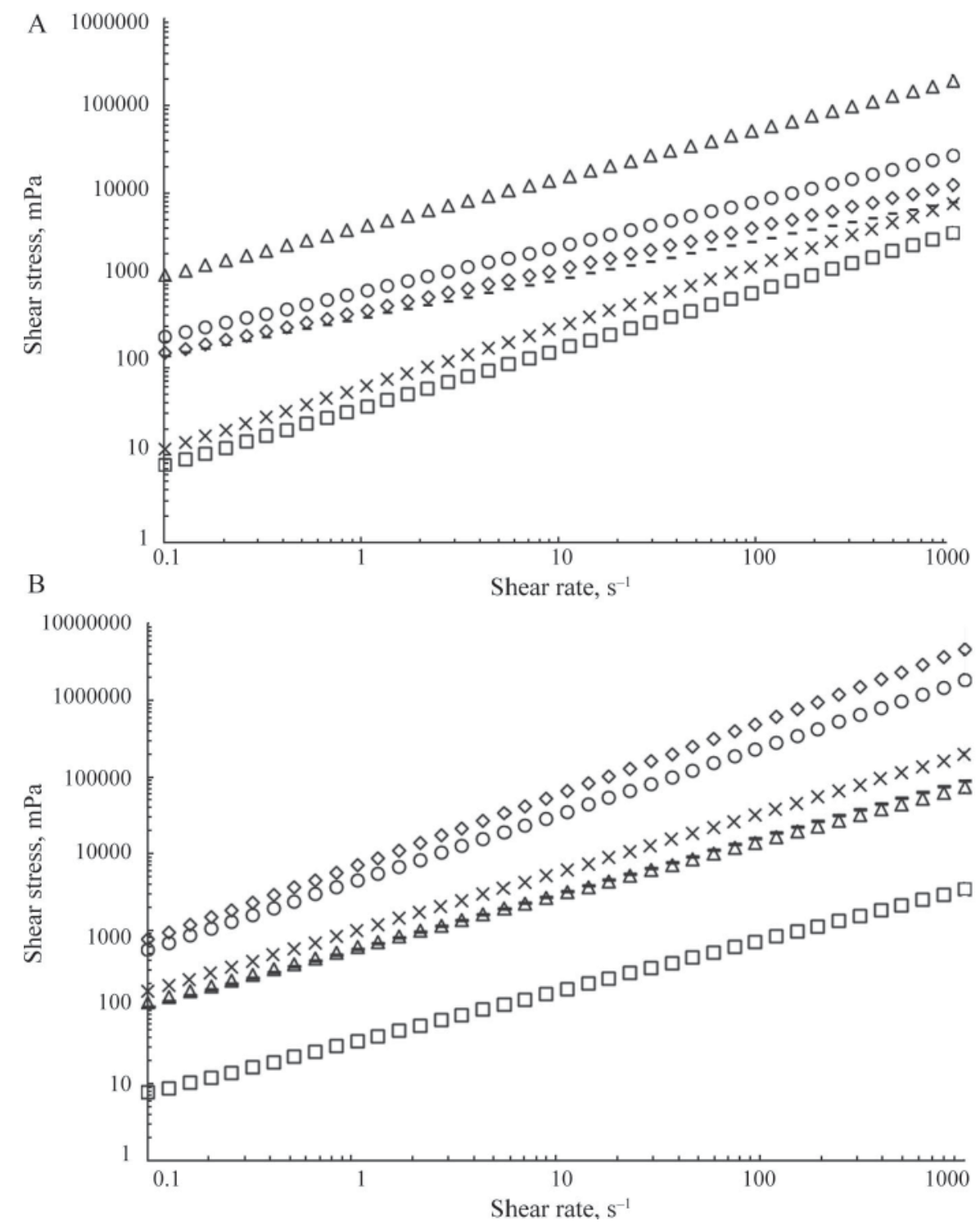

Fig. 1. Shear stress vs. shear rate for (A) R1-R5 and (B) R6-R10
A, $\square$ : Control; $\diamond: R 1 ; \triangle$ : R2; X: R3; -:R4; O: R5
$\mathrm{B}, \square$ : Control; $\diamond: \mathrm{R} 6 ; \Delta: \mathrm{R} 7 ; \mathrm{X}: \mathrm{R} 8 ;-$ :R9; O: R10 
stabilization. This behaviour is attributed to the high-viscous hydrocolloid network formed in continuous phase of doogh, which would bind water and casein and consequently reduces serum separation phenomenon (SYrbe et al., 1998). The non-Newtonian pseudoplastic behaviour appearing by increasing starch/inulin concentration supports the suggested mechanism in which protein particles are entrapped in a viscous network. Similar phenomenon has been previously observed for non-absorbant hydrocolloids such as guar and salep (Everett \& McLeod, 2005).

Application of inulin in dairy systems has been studied by STAFFolo and co-workers (2004) introducing various fibres, including inulin, into the yogurt. They observed improved physical stability and syneresis prohibition in yogurt during 21 days of storage by using $1.3 \%$ inulin in the formulation. Similar results have been reported by TABATABAIE and MORTAZAVI (2008) and GugGisberg and co-workers (2009) in yogurt and low-fat yogurt, respectively.

\subsection{Rheological characteristics}

Table 1 summarizes viscosity values for doogh samples after 30 days of storage. Viscosity increase by increasing the concentration of modified starch and long-chain inulin is easily seen.

The viscosity of samples R7 and R9, containing the minimum total content of starch and inulin, lies at the minimum value and does not show significant difference with the control sample. This confirms that starch and inulin does not have the capability to form gel network and offer acceptable viscosity at the concentrations below $0.3 \%$ and $1.18 \%$, respectively. Interestingly, increasing the content of each hydrocolloid individually to the values larger than the mentioned borders does not necessarily make significant differences. This phenomenon was observed by PASEEPHOL and co-workers (2008) that used 4\% inulin, individually, in yogurt. They reported lower values of apparent viscosity and complex viscosity compared with the control sample.

With increasing the total amount of the two independent variables, viscosity significantly increases, indicating the formation of a weak gel network that increases the apparent viscosity of contiguous phase through starch, hydrogen-bonded complexes of inulin, and yogurt protein aggregates (KIP et al., 2006). These interactions might increase molecular weight of milk proteins increasing contiguous phase viscosity of the product (TÁRREGA \& Costell, 2006).

\subsection{Flow behaviour}

Figure 1 shows shear stress versus shear rate for all prepared samples. Flow characteristics were investigated using Herschel-Bulkley model:

$$
\tau=\tau_{\mathrm{y}}+\mathrm{k} \dot{\gamma}^{\mathrm{n}}
$$

where $\tau, \tau, \mathrm{k}, \dot{\gamma}$, and $n$, respectively, refer to shear stress (Pa), yield stress (Pa), consistency coefficient $\left(\mathrm{Pa} . \mathrm{s}^{\mathrm{n}}\right)$, shear rate $\left(\mathrm{s}^{-1}\right)$, and flow behaviour index $(-)$. Comparing the accuracies of curves fitted to the measured data with increasing inulin and starch suggests HerschelBulkley as the appropriate model. Table 2 summarizes the parameters calculated on the basis of Herschel-Bulkley model for doogh samples. Effect of long-chain inulin and modified maize starch contents on the flow behaviour index (n) and consistency coefficient (k) after 30 days of production is observed. According to the flow behavior index values in Table 2, shear 
thinning behaviour is intensified with increasing inulin and starch concentration. Control sample and R2 show the maximum and minimum values of $\mathrm{n}$, respectively. Consistency coefficient, that is proportional to the fluid viscosity, reaches its maximum in sample R2.

Table 2. Flow behavior results fitted to Herschel-Bulkley model.

\begin{tabular}{lcccc}
\hline Samples & $\tau 0(\mathrm{~Pa})$ & $k\left(P a \cdot \mathrm{S}^{\mathrm{n}}\right)$ & $n(-)$ & $R^{2}$ \\
\hline R1 & $0.005 \pm 0.017^{\mathrm{a}}$ & $0.017 \pm 0.009^{\mathrm{ab}}$ & $0.665 \pm 0.117^{\mathrm{ab}}$ & $0.935 \pm 0.035^{\mathrm{a}}$ \\
R2 & $-0.869 \pm 1.234^{\mathrm{a}}$ & $0.038 \pm 0.012^{\mathrm{a}}$ & $0.505 \pm 0.026^{\mathrm{b}}$ & $0.950 \pm 0.014^{\mathrm{a}}$ \\
R3 & $0.011 \pm 0.004^{\mathrm{a}}$ & $0.001 \pm 0.000^{\mathrm{b}}$ & $0.983 \pm 0.005^{\mathrm{a}}$ & $0.935 \pm 0.021^{\mathrm{a}}$ \\
R4 & $-0.001 \pm 0.000^{\mathrm{a}}$ & $0.005 \pm 0.002^{\mathrm{b}}$ & $0.080 \pm 0.091^{\mathrm{a}}$ & $0.975 \pm 0.007^{\mathrm{a}}$ \\
R5 & $0.035 \pm 0.001^{\mathrm{a}}$ & $0.004 \pm 0.000^{\mathrm{b}}$ & $0.905 \pm 0.013^{\mathrm{a}}$ & $0.980 \pm 0.000^{\mathrm{a}}$ \\
R6 & $-0.004 \pm 0.002^{\mathrm{a}}$ & $0.011 \pm 0.002^{\mathrm{ab}}$ & $0.662 \pm 0.021^{\mathrm{ab}}$ & $0.975 \pm 0.007^{\mathrm{a}}$ \\
R7 & $0.026 \pm 0.004^{\mathrm{a}}$ & $0.002 \pm 0.000^{\mathrm{b}}$ & $0.977 \pm 0.016^{\mathrm{a}}$ & $0.975 \pm 0.007^{\mathrm{a}}$ \\
R8 & $0.012 \pm 0.010^{\mathrm{a}}$ & $0.012 \pm 0.005^{\mathrm{ab}}$ & $0.710 \pm 0.079^{\mathrm{ab}}$ & $0.960 \pm 0.000^{\mathrm{a}}$ \\
R9 & $0.004 \pm 0.005^{\mathrm{a}}$ & $0.002 \pm 0.001^{\mathrm{b}}$ & $0.937 \pm 0.070^{\mathrm{a}}$ & $0.960 \pm 0.014^{\mathrm{a}}$ \\
R10 & $0.051 \pm 0.039^{\mathrm{a}}$ & $0.023 \pm 0.015^{\mathrm{ab}}$ & $0.641 \pm 0.126^{\mathrm{ab}}$ & $0.955 \pm 0.021^{\mathrm{a}}$ \\
Control & $0.032 \pm 0.010^{\mathrm{a}}$ & $0.001 \pm 0.000^{\mathrm{ab}}$ & $0.991 \pm 0.001^{\mathrm{a}}$ & $0.962 \pm 0.001^{\mathrm{a}}$ \\
\hline
\end{tabular}

The results are expressed as mean \pm standard deviation. ${ }^{a, b}$ : Data followed by the same letter in a column are not significantly different $(\mathrm{P}>0.05)$.

Herschel-Bulkley parameters showed a decrease in viscosity with shear rate for all the samples containing starch and inulin, indicating pseudoplasticity, unlike the partially Newtonian behaviour observed for the control sample. This could be attributed to the higher dry matter content in the treated samples compared to the control sample, correlated with the deformation and disruption of modified starch gel network as well as inulin particle-gel structure under stress, followed by improved particle interactions and structural orientations encouraging shear thinning (KOKSOY \& KILIC, 2004; WOUTERS, 2011).

\subsection{Frequency sweep}

Regarding the above-mentioned results, in addition to the control sample, samples R1, R2, and R10 were selected for viscoelastic and particle size analysis.

Strain sweep oscillatory tests $(1 \mathrm{~Hz}, 0.01-100 \%)$ were conducted to determine the linear viscoelastic zone $(\approx 1 \%)$. Frequency sweep tests were then conducted in the linear zone at frequency range of $0.01-10 \mathrm{~Hz}$. Figure 2 shows elastic and loss modulus versus frequency for the selected samples. At all measured frequencies, G' was higher than G', indicating the presence of gel-like structure formed by starch hydration as well as inulin gel-particle network interacting with starch and casein micelles. The contradictory behaviour of the control sample (G'>G') is attributed to the absence of hydrocolloid (JENSEN et al., 2010). The elastic and viscous modulus for sample R2 are the highest. This shows the higher physical stability of R2 during storage time that is confirmed by the serum separation results. The cross-over of G" and G' at $0.01 \mathrm{~Hz}$ for the control sample could be indicative of high 
instability leading to phase separation as seen in serum separation test (StefFe, 1996). A significant effect of the interactions between the inulin type, the inulin concentration, and the starch concentration on gel formation, G', and G" was observed by GonZALEZ-Tomís and co-workers (2008) in inulin-starch-based dairy systems.

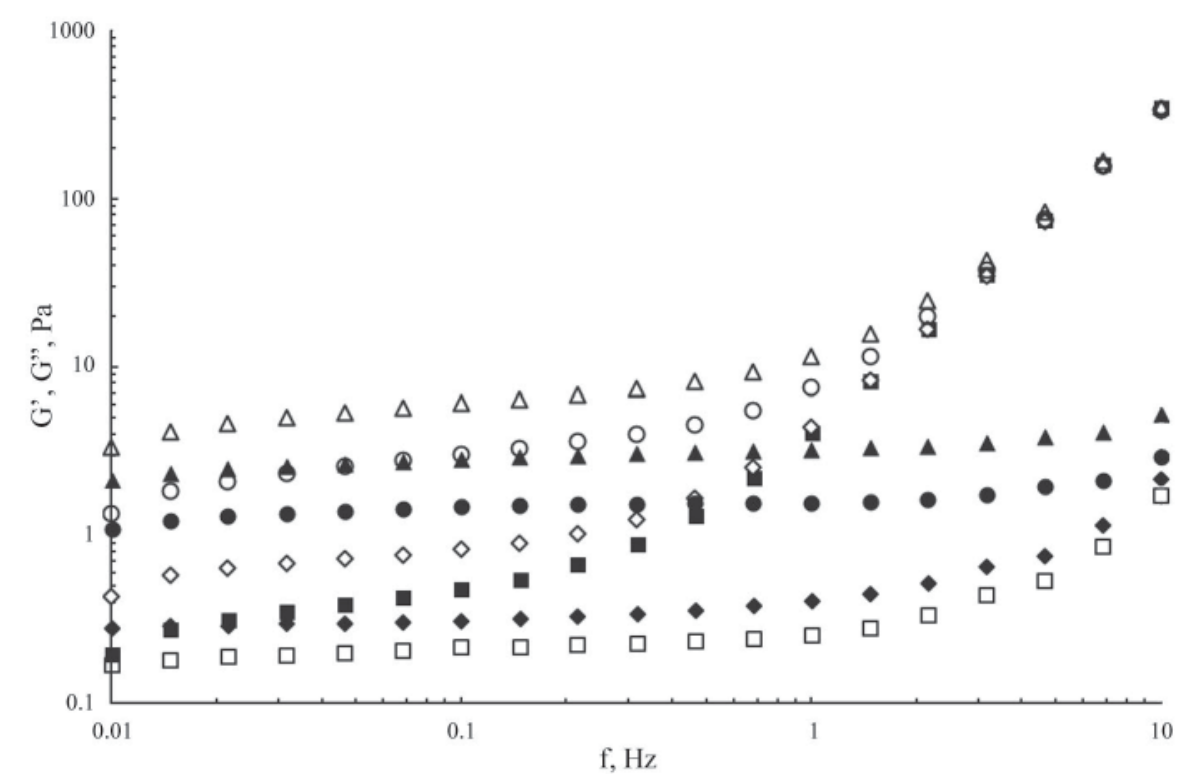

Fig. 2. Elastic and loss modulus vs. frequency for R1, R2, R10, and the control sample

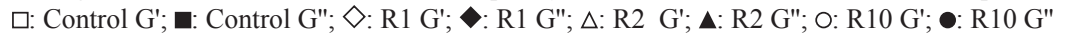

\subsection{Particle size distribution}

Table 3 summarizes the particle size test results for samples R1, R2, R10, and the control sample.

Table 3. Particle size distribution results for doogh samples

\begin{tabular}{lccccc}
\hline Samples & Span & Uniformity & $\mathrm{d}(0.1)$ & $\mathrm{d}(0.5)$ & $\mathrm{d}(0.9)$ \\
\hline Control & $2.29 \pm 0.03^{\mathrm{a}}$ & $0.81 \pm 0.007^{\mathrm{a}}$ & $1.63 \pm 0.02^{\mathrm{b}}$ & $4.75 \pm 0.73^{\mathrm{d}}$ & $12.55 \pm 0.22^{\mathrm{d}}$ \\
R1 & $1.99 \pm 0.07^{\mathrm{b}}$ & $0.63 \pm 0.002^{\mathrm{b}}$ & $1.22 \pm 0.13^{\mathrm{d}}$ & $27.24 \pm 0.02^{\mathrm{b}}$ & $55.44 \pm 0.27^{\mathrm{b}}$ \\
R2 & $1.92 \pm 0.22^{\mathrm{c}}$ & $0.59 \pm 0.003^{\mathrm{c}}$ & $1.50 \pm 0.01^{\mathrm{c}}$ & $27.21 \pm 0.07^{\mathrm{c}}$ & $53.92 \pm 0.01^{\mathrm{c}}$ \\
R10 & $1.85 \pm 0.01^{\mathrm{d}}$ & $0.53 \pm 0.001^{\mathrm{d}}$ & $1.76 \pm 0.52^{\mathrm{a}}$ & $29.40 \pm 0.32^{\mathrm{a}}$ & $56.24 \pm 1.03^{\mathrm{a}}$ \\
\hline
\end{tabular}

The results are expressed as mean \pm standard deviation. ${ }^{\text {a,b,c,d }}$ : Data followed by the same letter in a column are not significantly different $(\mathrm{P}>0.05)$.

The mean particle size is lower for the control sample compared to the treated samples. As for the control sample, $\mathrm{D}_{0.9}$ is smaller than $12.55 \mu \mathrm{m}$, while it exceeds $50 \mu \mathrm{m}$ for the other 
samples. One peak with a span of 2.29 appearing in Figure 3 is attributed to the aggregation of micelles during the one month storage time, whereas R1, R2, and R10 show two peak points. The first peak is related to aggregated micelles and/or inulin particle-gel crystals, which have not been adsorbed on casein micelles. The second peak point is sharper than the first one for all three samples, and corresponds to the hydrated maize starch granules and casein-inulin complexes. According to Wouters (2011), hydrated inulin gel-particle crystals have a typical dimension of $0.5-3 \mu \mathrm{m}$, therefore if there were no casein micelles in the samples, the two peak could have been ascribed to inulin and hydrated starch granules, respectively, but in the presence of casein micelles and their interactions with inulin gelparticles, a large portion of free aggregated micelles shift to the second part of curve, broadening the second peak. As the size scale of gel-particles is close to that of inulin aggregated micelles, in the three samples containing inulin and modified starch, small part of inulin content in each sample together with the aggregated micelle particles form the first peak. The second peak appeared for the hydrated starch granules and inulin gel-particles/ casein micelles complexes. According to the evidences of Wouters (2011) indicating the 5-30 micronic granule size for waxy maize starch, appearance of the second peak is confirmed to be representing the hydrated waxy maize starch granules and casein-inulin complexes.

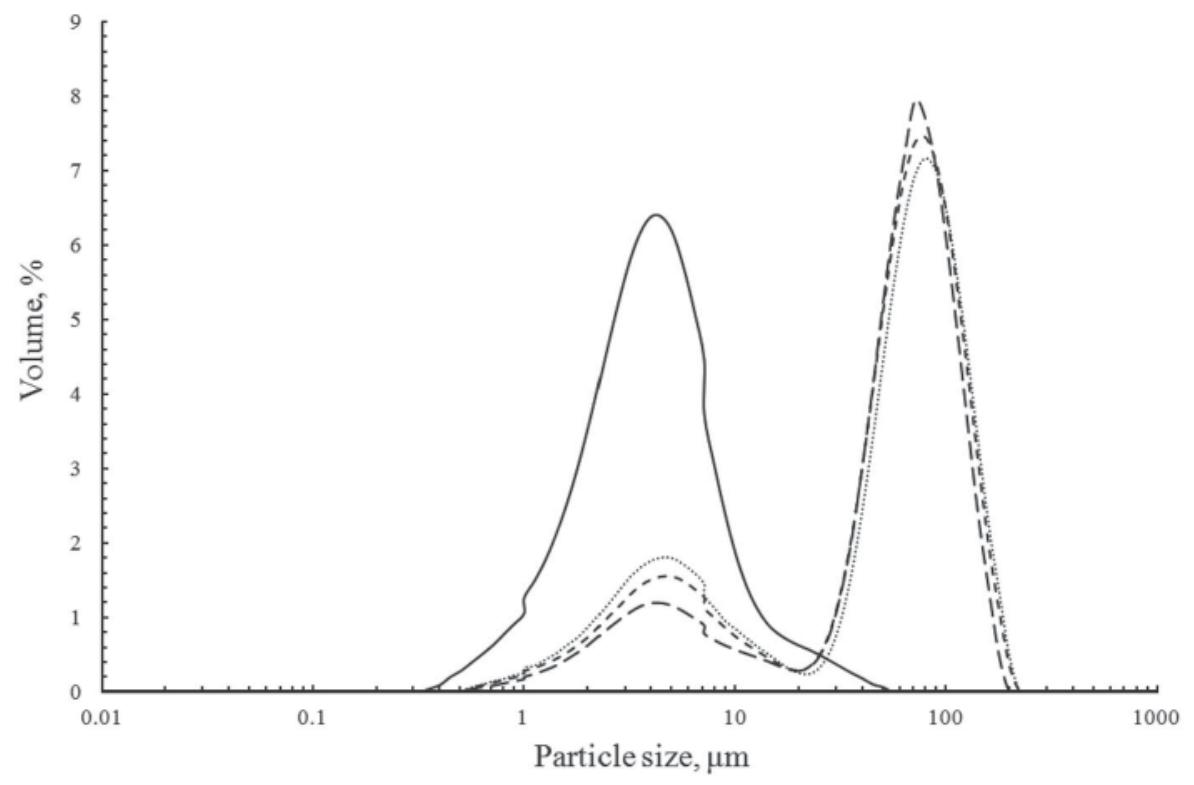

Fig. 3. Particle size distribution for R1, R2, R10, and the control sample - Control; ….....: R1; ----: R2; --: R10

\subsection{Response surface method optimization}

Based on the experimental results, design expert software introduced R2 as the optimized run, which contains $0.5 \%$ modified starch and $2 \%$ long-chain inulin. The values predicted by the response surface method for the response variables are involved Table 4. Characterization 
of the suggested optimized run by the response surface method was satisfactorily near the measured response variables (see Tables 1 and 2).

Table 4. Response variables predicted by the response surface method

\begin{tabular}{|c|c|c|c|c|c|}
\hline \multicolumn{2}{|c|}{ Independent variables } & \multicolumn{4}{|c|}{ Predicted response variables } \\
\hline Modified starch & Inulin & $\begin{array}{c}\text { Phase separation after } 30 \\
\text { days (\%) }\end{array}$ & $\begin{array}{l}\text { Viscosity after } 30 \text { days } \\
\text { (mPa.s) }\end{array}$ & $k\left(P a . s^{\mathrm{n}}\right)$ & $n(-)$ \\
\hline 0.5 & 2 & 52 & 20.71 & 0.033 & 0.511 \\
\hline
\end{tabular}

\section{Conclusions}

Utilization of long-chain inulin and modified maize starch in doogh samples was observed to improve qualitative characteristics of samples. Serum separation, viscosity, flow behaviour, and viscoelastic properties of formulated samples containing the two hydrocolloids showed significant difference compared to the control sample $(\mathrm{P}<0.05)$. Accordingly, combined application of prebiotic long-chain inulin and modified starch synergistically improves physical and rheological characteristics of doogh samples, especially for sample R2 (containing 2\% inulin and $0.5 \%$ starch) and R10 (containing 2\% inulin and $0.5 \%$ starch).

\section{References}

Ahmed, J. \& Ramaswamy, H.S. (2004): Effect of high-hydrostatic pressure and concentration on rheological characteristics of xanthan gum. Food Hydrocolloids, 18, 367-373.

Alimi, M., Mizani, M., Naderi, G. \& Shoкоoнi, S. (2013): Effect of inulin formulation on the microstructure and viscoelastic properties of low-fat mayonnaise containing modified starch. J. Appl. Polym. Sci., 130, 801-809.

Azarikia, F. \& ABbasi, S. (2010): On the stabilization mechanism of doogh (Iranian yoghurt drink) by gum tragacanth. Food Hydrocolloids, 24, 358-363.

Bot, A., Erle, U., Vreeker, R. \& Agterof, W.G. (2004): Influence of crystallisation conditions on the large deformation rheology of inulin gels. Food Hydrocolloids, 18, 547-556.

Dickinson, E. (1998): Stability and rheological implications of electrostatic milk protein-polysaccharide interactions. Trends Food Sci. Tech., 9, 347-354.

Everett, D.W. \& McLeod, R.E. (2005): Interaction of polysaccharide stabilizers with casein aggregates in stirred skim-milk. Int. Dairy J., 15, 1175-1183.

Glibowski, P. \& Kowalska, A. (2012): Rheological, texture and sensory properties of kefir with high performance and native inulin. J. Food Eng., 111, 299-304.

Golchоовi, L., Alimi, M., Sнокоонi, S. \& Yousefi, H. (2016): Interaction between nanofibrillated cellulose with guar gum and carboxy methyl cellulose in low-fat mayonnaise. J. Texture Stud., 47, 403-412.

Gonzalez-Tomás, L., Coll-Marqués, J. \& Costell, E. (2008): Viscoelasticity of inulin-starch-based dairy systems: Influence of inulin average chain length. Food Hydrocolloids, 22, 1372-1380.

Gorj, E.G., Моhammadifar, M.A. \& Ezzatpanah, H. (2011): Influence of gum tragacanth, Astragalus gossypinus, addition on stability of nonfat doogh, an Iranian fermented milk drink. Int. J. Dairy Technol., 64, 262-268.

Guggisberg, D., Cuthbert-Steven, J., Piccinali, P., Butikofer, U. \& Eberhard, P. (2009): Rheological, microstructural and sensory characterization of low-fat and whole milk set yoghurt as influenced by inulin addition. Int. Dairy J., 19, 107-115.

JENSEn, S., Rolin, C. \& IpSEn, R. (2010): Stabilisation of acidified skimmed milk with HM pectin. Food Hydrocolloids, 24, 291-299.

Kip, P., Meyer, D. \& Jellema, R. (2006): Inulins improve sensoric and textural properties of low-fat yoghurts. Int. Dairy J., 16, 1098-1103.

Koksoy, A. \& KiLIC, M. (2004): Use of hydrocolloids in textural stabilization of a yoghurt drink, ayran. Food Hydrocolloids, 18, 593-600. 
Mircholi Borazagh, A. \& Sedaghat, N. (2011): The effect of temperature and packaging on the shelf life of noncarbonated doogh. J. Innov. Food Sci. Tech., 2, 1-8. (In Persian).

Paseephol, T., Small, D.M. \& Sherkat, F. (2008): Rheology and texture of set yogurt as affected by inulin addition. J. Texture Stud., 39, 617-634.

Staffolo, M.D., Bertola, N. \& Martino, M. (2004): Influence of dietary fiber addition on sensory and rheological properties of yogurt. Int. Dairy J., 14, 263-268.

StefFe, J.F. (1996): Rheological methods in food process engineering. Freeman Press, East Lansing. pp. $294-349$.

Syrbe, A., Bauer, W. \& Klostermeyer, H. (1998): Polymer science concepts in dairy systems - an overview of milk protein and food hydrocolloid interaction. Int. Dairy J., 8, 179-193.

Tabatabaie, F. \& Mortazavi, A. (2008): Influence of lactulose on the survival of probiotic strains in yoghurt. World Applied Sciences Journal (WASJ), 3, 88-90.

TÁrrega, A. \& Costell, E. (2006): Effect of inulin addition on rheological and sensory properties of fat-free starchbased dairy desserts. Int. Dairy J., 16, 1104-1112.

Villegas, B. \& Costell, E. (2007): Flow behaviour of inulin-milk beverages. Influence of inulin average chain length and of milk fat content Int. Dairy J., 17, 776-781.

Wouters, R. (2011). Inulin. -in: ImEson, A. (Ed.) Food stabilisers, thickeners and gelling agents. Wiley Blackwell Publishing Ltd. pp. 180-197. 